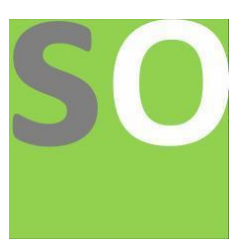

Article title: Google Earth for Land Use Land Cover Detection in the Case of Guntur Urban, Andhra Pradesh, for Public Health Use

Authors: Yuvaraju Chinnam[1]

Affiliations: JAWAHARLAL NEHRU TECHNOLOGICAL UNIVERSITY KAKINADA[1]

Orcid ids: 0000-0002-7156-2452[1]

Contact e-mail: chinnamyuvraj@gmail.com

License information: This work has been published open access under Creative Commons Attribution License http://creativecommons.org/licenses/by/4.0/, which permits unrestricted use, distribution, and reproduction in any medium, provided the original work is properly cited. Conditions, terms of use and publishing policy can be found at https://www.scienceopen.com/.

Preprint statement: This article is a preprint and has not been peer-reviewed, under consideration and submitted to ScienceOpen Preprints for open peer review.

Funder: NRDMS GOVERNMENT OF INDIA

DOI: 10.14293/S2199-1006.1.SOR-.PPYQZQI.v1

Preprint first posted online: 28 February 2020

Keywords: LULC, mapping, disease, Mosquitos, Google Earth, mosquito-borne diseases, public health 


\title{
GOOGLE EARTH FOR LAND USE LAND COVER DETECTION IN \\ THE CASE OF GUNTUR URBAN, ANDHRA PRADESH FOR PUBLIC HEALTH USE
}

\author{
Chinnam Yuvaraju*, Research Scholar, Spatial Information Technology, JNTUK \\ Dr.Iyyanki V. Murali Krishna, Dr. Raja Ramanna Distinguished Fellow, DRDO \\ Dr.K.V.S.G.Murali Krishna, Professor of Civil Engineering, JNTUK \\ *Corresponding author: chinnamyuvraj@gmail.com
}

\begin{abstract}
:
The land use/cover (LULC) pattern is a unique method approached for identifying parameters in developing programs of human needs and welfare, specifically for the planning and implementation purpose. This method enables researchers to understand the important information from and every single parameter involved. In the study, we could count upon the information on various parameters that help to identify the breeding sites and the spread of mosquitos. The study is conducted in the Guntur Urban, state of Andhra Pradesh, wherein the LULC patterns are investigated by using Google Earth imagery. Various relatively static parameters like Dense Vegetation, Sparse Vegetation, Water bodies, and urban area cover are taken into consideration for the determination of (Aedes agypti) dengue causing mosquito-breeding habitats, [6-8],. In this study LULC is used to determine the risk zones that would enable to carry forward the necessary actions to reduce the mosquito-borne diseases, polygon overlay is employed to generate risk maps of the study area, and these risk zones could be further processed for high, moderate and low-risk areas.
\end{abstract}

Keywords: LULC, mapping, disease, Mosquitos, and determinants

\section{INTRODUCTION:}

Remote sensing and Geographical Information systems (GIS) are playing a vital role in the detection, identification, mapping, and classification of mosquito larval habitats [1-5] Land use and Land cover change (LULC) plays an essential role in understanding the geographical variations of the chosen landscape that enables to substantiate the change determinants. The growing population and inevitable changes result in the rising concerns that are catastrophic; these are caused by mismanagement of water bodies, dense vegetation, sparse vegetation, and urban areas.

Remote sensing is a widely accepted and sophisticated technique employed to find these complex changes in the environment when it combines with GIS, and the outcomes provide a better understanding of the scenarios and take necessary actions to reduce the impacts. In this study, Imagery of the study area is collected from Google Earth. Google Inc. provides Google earth, is a virtual globe programming that maps the earth by the superimposition of highresolution satellite images. The spatial pattern of LULC enables us to find the dynamic changes in the area and be able to determine the occurrence of the disease and spread in the location. 
GIS helps to identify land-use changes more accurately, and it includes precision tools to get detailed information about land use and land cover. For determining the disease outbreak and spread areas, the area of the polygon overlay tools can be used.

\section{STUDY AREA:}

Guntur is now in the Capital Region of Andhra Pradesh is situated on the bank of Krishna river at the longitude and Latitude between 16'390" N and 80'0088” E. at a mean sea level of $26 \mathrm{~m}$. It sprawls an area of $168.5 \mathrm{Km} 2$ in that $88.50 \mathrm{Km} 2$ is classified as an urban area. Guntur is governed by two administrative bodies namely the Guntur Municipal Corporation (GMC) and Guntur Metro City both are eventually comes under Capital Region Development Authority (CRDA), GMC is responsible for public health activities. The GMC comprises 58 wards that cover the most significant part. The study area is spread at $88.5 \mathrm{~km} 2$ and has population 7, 73,568. The Indian red-chilies capital city Guntur remains hot in summer, humid in monsoon season. Average temperatures of Guntur are $28.5^{\circ} \mathrm{C}$. In summers, the heatwave in Guntur is immense and adequate precautions have to be taken before going out in the afternoons. Rainfall season in Guntur is between June to September and the average rainfall recorded is $830 \mathrm{~mm}$.

\section{MATERIALS AND METHODS:}

\section{DATA ACQUISITION:}

Precisely the Satellite imagery is collected from the Google earth application dated 23rd May 2015 is used for image classification. The spatial resolution of the image is 1.40 meters. QGIS 2.18 is the software application used for classification. After Georeferencing of the Google Earth image, spatial tools extract the study area and identifying various parameters like water bodies, urban areas, dense vegetation, and sparse vegetation are selected for image classification. The shape of the study area is taken with reference to Google maps by overlaying it on the satellite imagery [2]. To extract the shapefile polygon tool is used in QGIS 2.18. 


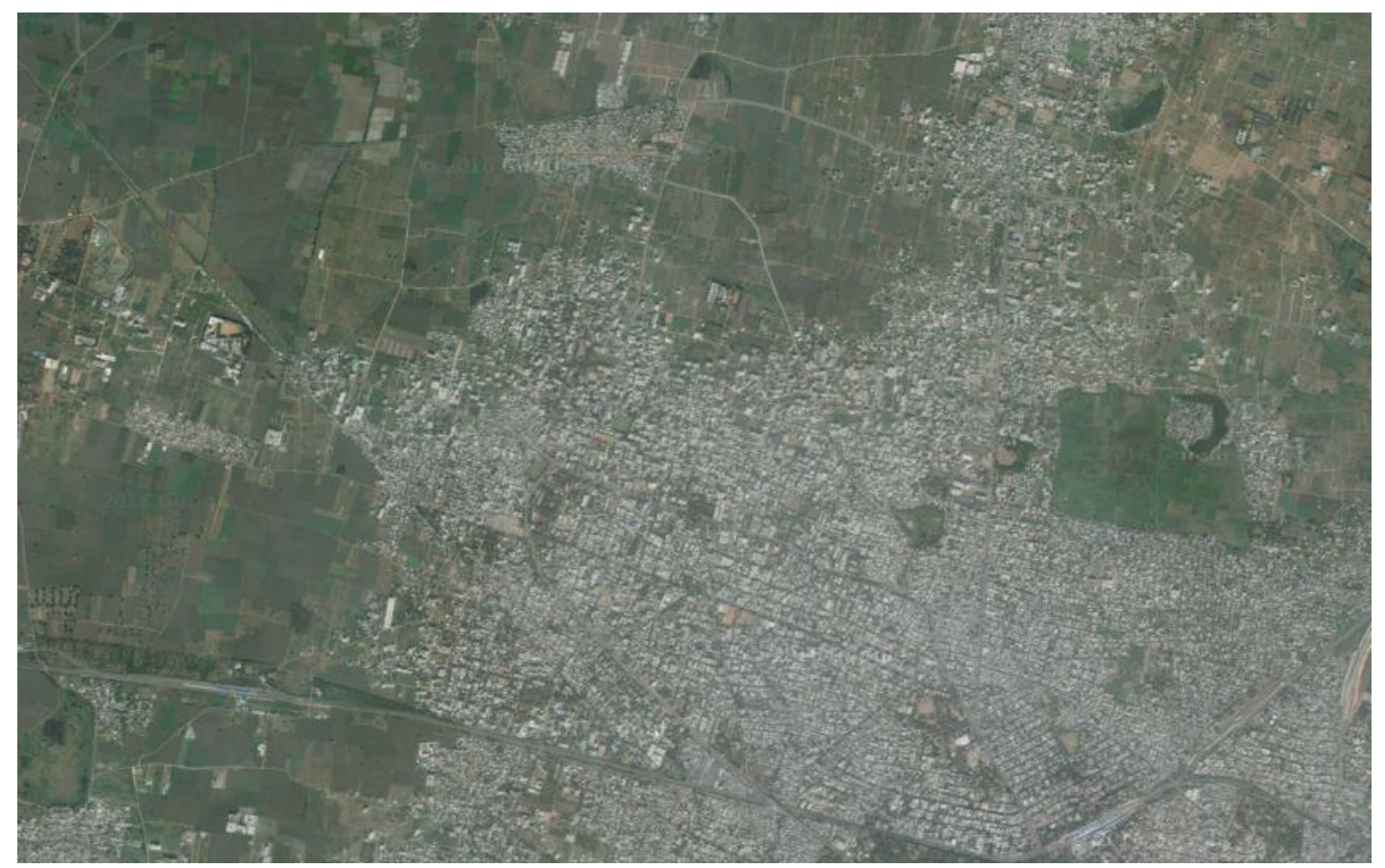

Fig 1 : Satellite Imagery of the study area (Source: GE)

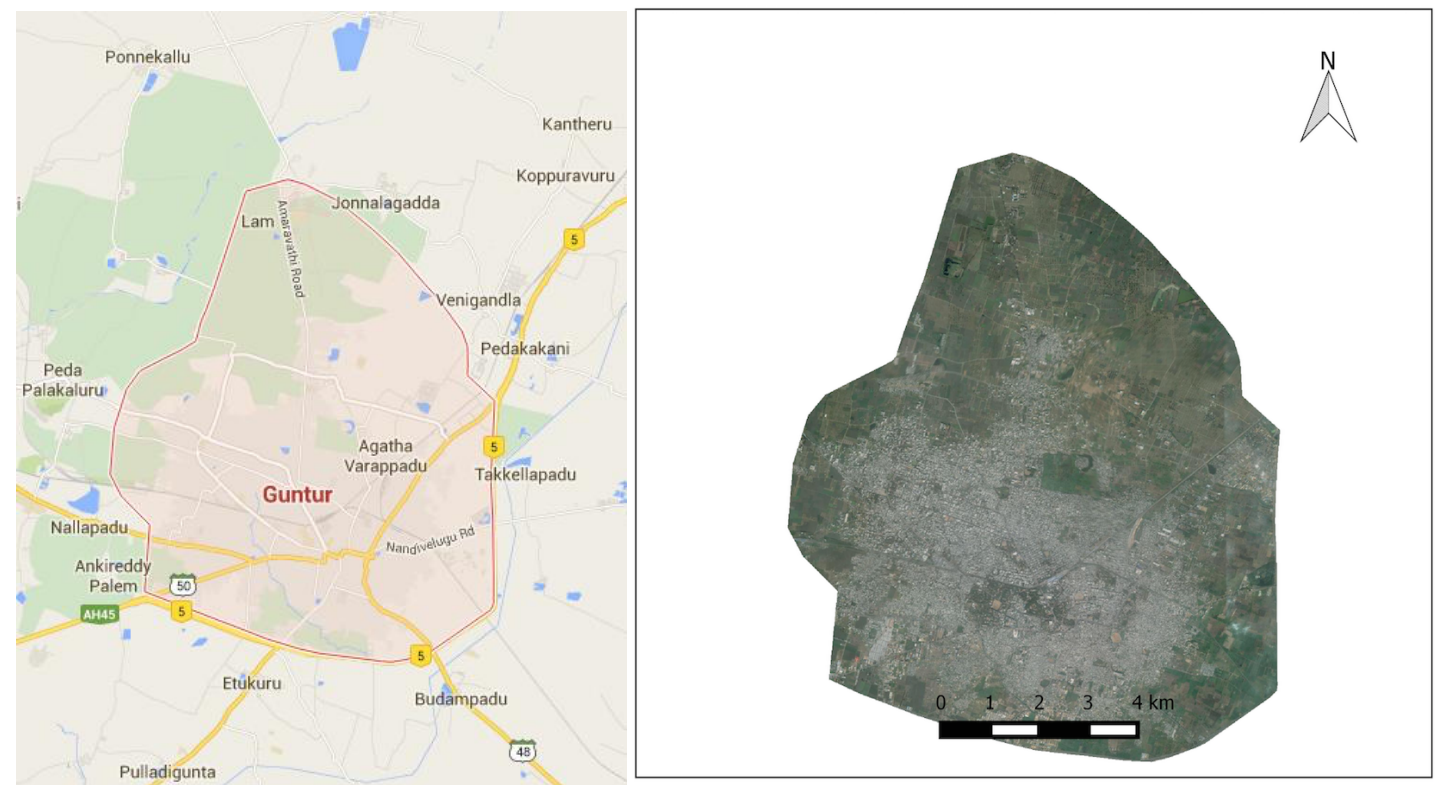

Fig 2: Shape file of study area (GM) Fig 3: Extracted satellite image of Guntur urban

\section{LAND USE/COVER FEATURES:}

The static parameters identified in this study are the main features useful for land use/ cover classifications. Presumably, these are mainly considered the determinants for disease prevalence. This research will comprise the land use/cover features of Semiurban croplands, Urban Open lands/sparse vegetation, dense urban vegetation, water bodies, and urban area, as shown in Table 1.

\section{RESULTS:}

Pertain to the identification of parameters in imagery; supervised classification is performed to make LULC in the region. Supervised image classification is done to 
study the area, wherein the analysts train the computer to recognize patterns in the data by selecting pixels that represent patterns or land cover features, The signature files thus created are then used in the classification process where each pixel is categorized into the land cover class it mostly resembles. Products of this process being a thematic map, tables of statistics of the various lands cover classes and digital data files that can be included in a GIS.

Table 1: Percentage of land use parameters.

\begin{tabular}{|c|c|c|l|}
\hline Sl.No. & FEATURE & AREA (Sq.K.m.) & PERCENTAGE \\
\hline 1 & Semi urban crop lands & 44.515 & $50.1 \%$ \\
\hline 2 & Urban Open lands/sparse vegetation & 5.632 & $06.3 \%$ \\
\hline 3 & Dense urban Vegetation & 1.391 & $01.5 \%$ \\
\hline 4 & Water bodies & 0.882 & $00.99 \%$ \\
\hline 5 & Urban Area & 37.008 & $41.6 \%$ \\
\hline \multicolumn{2}{|r|}{ Total } & 88.819 & 100 \\
\hline
\end{tabular}

Land Use Land Cover-Guntur Urban Area

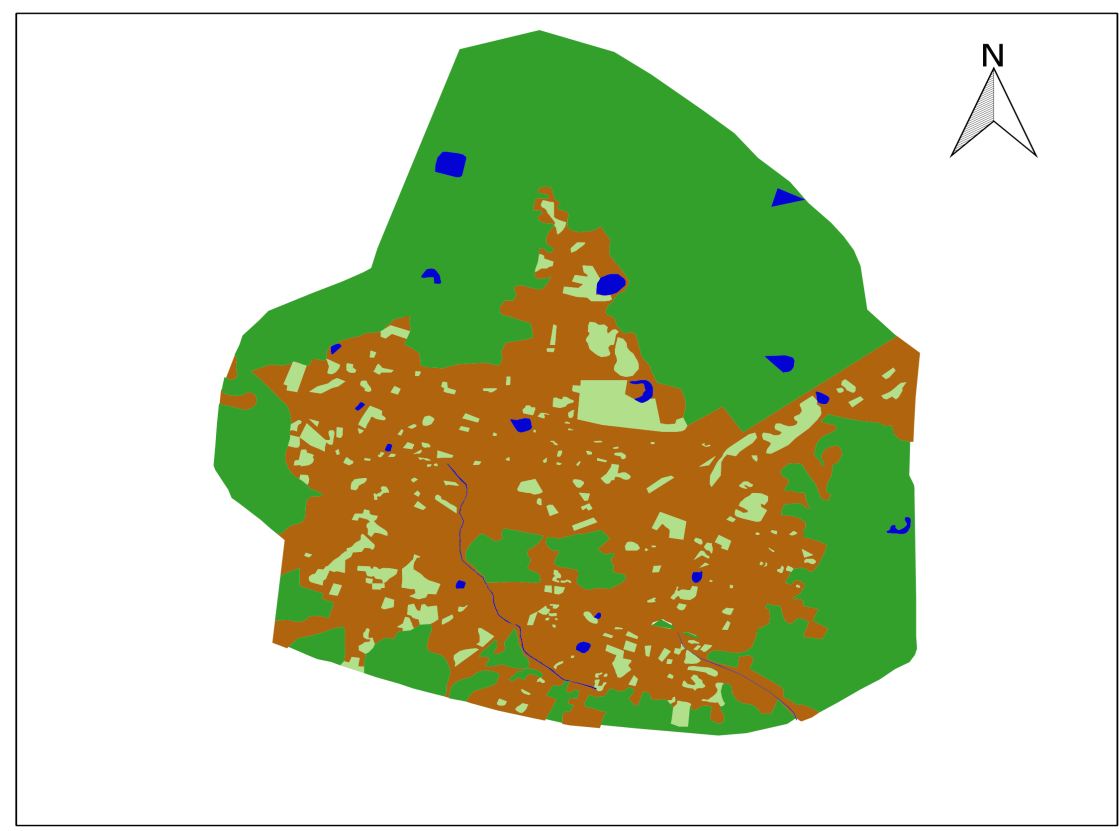

Legend

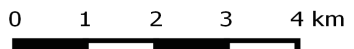

Water Bodies

Semi-Urban Crop Lands

Dense Urban Vegetation

Urban Open Lands/Sparse Vegetation

Urban Area 


\section{CONCLUSION:}

In most of the cases, the Land use/land cover is used to determine the change in the particular area/region to know the changes or improvements taken place in the study area. Unlike regular research, in this paper, the author would like to portray the current scenario of the land use and intent to draw a picture to build decision rules that are helpful to the researchers to find out the causes and effect of the land use aspects in disease prevalence and related issues. This paper would also be handy for understanding the naïve users to understand GIS technology because, in this study, the satellite image has been taken from Google earth, and urban shape is also made from Google maps.

\section{REFERENCES:}

1.Allen Hightower W, Maurice Ombok, Richard Otieno, Richard Odhiambo, Aggrey Oloo j, Altaf Lal A. et al. A Geographical Information Systems (GIS) applied to a malaria field study in western Kenya, Am J Trop Med Hyg. 1998; 58(3):266-272.

2.Bartholome, E.; Belward, A.S. GLC2000: A new approach to global land cover mapping from Earth observation data. Int. J. Remote Sens. 2005, 26, 1959-1977.

3.Beck LR, Rodriguez MH, Dister SW, Rodriguez AD, Rejmankova E, Ulloa AR. et al. Remote sensing as a landscape epidemiologic tool to identify villages at high risk for malaria transmission. Am J Trop Med Hyg. 1994; 51(3):271-80.

4.Booman M, Durrheim DN, La Grange K, Martin C, Mabuza AM, Zitha A. et al. Using a geographical information system to plan a malaria control programme in South Africa. Bull World Health Organ, 2000; 78(12):1438-44.

5.Cross ER, Newcomb WW, Tucker CJ. Use of weather data and remote sensing to predict the geographic and seasonal distribution of Phlebotomus papatasi in southwest Asia. Am J Trop Med Hyg. 1996; 54(5):530-6.

6.Curran PJ, Atkinson PM, Foody GM, Milton EJ. Linking remote sensing, land cover and disease. Adv Parasitol, 2000; 47:37-80.

7.Gimnig, John \& Hightower, Allen \& Hawley, William. (2005). Application of geographic information systems to the study of the ecology of 
mosquitoes and mosquito-borne diseases. Wageningen UR Frontis Series. 9.

8.Hay SI, Omumbo JA, Craig MH, Snow RW. Earth observation, geographic information systems and Plasmodium falciparum malaria in sub-Saharan Africa. Adv Parasitol, 2000; 47:173-215.

9.Hayes RO, Maxwell EL, Mitchell CJ, Woodzick TL. Detection, identification, and classification of mosquito larval habitats using remote sensing scanners in earth- orbiting satellites. Bull World Health Organ, 1985; 63(2):361-74.

10. Kitron U, Pener H, Costin C, Orshan L, Greenberg Z, Shalom U. Geographic information system in malaria surveillance: mosquito breeding and imported cases in Israel. 1992; Am J Trop Med Hyg. 1994; 50(5):5506. 